\title{
Behavioural response of green peach aphid Myzus persicae (Sulzer) to volatiles from different rosemary (Rosmarinus officinalis L.) clones
}

\author{
Tarek Dardouri*, Laurent Gomez*, Alexandra Schoeny", Guy Costagliola* and Hélène Gautier*(i) \\ *UR1115 PSH Plantes et Systèmes de Culture Horticoles, INRA, F84914 Avignon, France and ${ }^{\dagger}$ Pathologie Végétale, INRA, 84140 Montfavet, France
}

\begin{abstract}
Previous studies have shown that rosemary (Rosmarinus officinalis L.) can serve as a companion plant to control Myzus persicae (Sulzer) because of the repellent effect of certain volatile organic compounds (VOCs) that it emits. In the present study, we investigated which of five clones of rosemary may reveal a repellent effect on $M$. persicae and aimed to determine the possible VOCs involved.

2 Analyses of the mixtures of VOCs released by the different clones revealed the presence of 15 main components. However, each clone was characterized by a specific volatile profile showing the existence of marked chemical variability.

3 By testing the identified VOCs individually, using a dual-choice olfactometer, we observed that five volatiles had a significant repulsive effect on $M$. persicae: bornyl acetate, camphor, $\alpha$-terpineol, terpinene-4-ol and geranyl acetone. In addition, only one clone of rosemary elicited a significant repulsive action.

4 Nevertheless, all of the tested clones released compounds that are repellent to the aphid when tested individually. Therefore, the emission of individual volatiles by a rosemary plant is not sufficient to elicit a repellent effect.

5 The concentration, proportion and even the association/synergy of VOCs in the released olfactory bouquets can probably explain these contrasting results and are worthy of additional exploration in future studies.
\end{abstract}

Keywords Agroecology, aphid, companion plants, Myzus persicae, repulsion, rosemary, volatile organic compounds.

\section{Introduction}

Aphids (Hemiptera, Aphididae) are piercing-sucking insects that feed on phloem sap, which results in severe damage to the host plants. Myzus persicae (Sulzer), the so-called green peach aphid, causes considerable damage to several crops not only by removing phloem sap from plants, but also by transmitting plant viruses (Blackman \& Eastop, 2000). This polyphageous insect, for which the primary host is the peach tree, causes significant damage to many secondary hosts, such as pepper species in greenhouses (Sanchez et al., 2011).

To limit the severity of the damage caused by this pest, several control methods have been carried out, among which chemical control methods are the most widespread. Despite being rapid and effective, the chemical control methods present

Correspondence: Hélène Gautier. Tel.: +33 (0)43272 2345; e-mail: helene.gautier@inra.fr several disadvantages as a result of their harmful effects on the environment and the continuous development of resistant populations (Bass et al., 2014).

To solve this problem and to ensure sustainable, economically competitive and ecologically intensive agriculture, the scientific community has adopted a strategy for the development of alternative control methods (Penvern et al., 2010). One of these methods is based on the association of cultivated crops with companion plants aiming to provide services to the agro-ecosystem (Ben Issa et al., 2017a). This agro-ecological strategy presents a promising alternative control method for maintaining phytophagous populations below their economic threshold, thus reducing the frequency of phytosanitary treatments without significantly reducing the level of production of the target crop (Uvah \& Coaker, 1984; Malézieux et al., 2009; Tang et al., 2012). The different mechanisms explored with these companion plants are repulsion (plants with repellent properties) and attraction (trap plants). Furthermore, companion plants are able to mask the volatile 
emissions from host plants and can also attract natural enemies to control phytophagous populations (Ben Issa et al., 2017a).

Regarding the repulsion mechanism (Deletre et al., 2016), the choice of species associated with the crop to be protected remains paramount for the strategy to succeed (Shrivastava et al., 2010) and is dependent on several factors. In addition to the ability to disturb the behaviour of aphids, criteria such as the phenology, hardiness and commercial exploitation of these plants need to be considered (Castro et al., 2017).

Recent research has shown that the presence of rosemary (Rosmarinus officinalis, Lamiaceae) in the vicinity of sweet pepper plants hinders the development of $M$. persicae populations (Ben Issa et al., 2016, 2017b). Rosemary is an aromatic plant that appears to meet the criteria required for a companion plant for the control of green peach aphid in Mediterranean horticultural crops. According to several studies (Hori, 1998, 1999a; Ben Issa et al., 2016, 2017b), the remote action of rosemary plants, eliciting repulsive effects in $M$. persicae is related to the emission of volatile organic compounds (VOCs). These VOCs, which are not essential for cell growth and development, accumulate in specialized anatomical structures called trichomes (Marin et al., 2006). The mixture of VOCs, which gives rosemary its characteristic odour, is mainly composed of monoterpenes $\left(\mathrm{C}_{10} \mathrm{H}_{16}\right.$ compounds). Chromatographic analyses of rosemary essential oils and plants show that the main VOCs are bornyl acetate, borneol, camphene, camphor, eucalyptol (1,8-cineole), linalol, verbenone and $\alpha$-pinene (Angioni et al., 2004; Miresmailli et al., 2006; Chopa \& Descamps, 2012; Zhang et al., 2014a; Sadeh et al., 2017). It can be hypothesized that the efficacy of these plants is related to the emission level of one or more of these compounds, which would increase as their production increases. However, Ben Issa et al. (2017b) found that the range of action of the companion plants is quite limited and that effective protection requires such a density that it can be restrictive and cause a decline in the yield of the main crop. Therefore, it is imperative to optimize VOC production. In this sense, genetic selection can be an essential lever for optimizing the effectiveness of rosemary and promoting its use by producers. Indeed, VOC production varies quantitatively and qualitatively according to the cultivars (Satyal et al., 2017), generating a variable olfactory response from aphids (da Costa et al., 2010; Staudt et al., 2010; Rajabaskar et al., 2013; Schröder et al., 2015). Still, by the same logic, understanding the action modes of companion plants and identifying the molecules involved should help us to select the most successful genotypes. However, there is little information available on this topic, especially with respect to the dualistic interaction between plants and insects via VOCs (Hori, 1999b).

The present study aimed to assess the effect of rosemary genetic variability on its ability to disrupt the behaviour of green peach aphids. The olfactory bouquets of five rosemary clones were analyzed by gas chromatography-mass spectrometry (GC-MS) and their VOC profiles were established. The repellent properties of the studied clones, as well as those of each of the VOCs identified in the olfactory bouquets, were assessed in dual-choice bioassays using olfactometers (Ameline et al., 2007; Alvarez et al., 2007). In the end, our ultimate goal was to establish a link between aphid repellence and the presence of certain VOCs from rosemary clones.

\section{Materials and methods}

\section{Aphid rearing}

Myzus persicae were obtained by mass rearing (clone Mp05) from a fundatrix collected from a peach orchard of the French National Institute for Agricultural Research (INRA) of Avignon (France) (Sauge et al., 2010). The insect culture was maintained on young pepper plants under controlled rearing conditions, comprising an LD $16: 8 \mathrm{~h}$ photocycle at $22 \pm 1{ }^{\circ} \mathrm{C}$ and $60-70 \%$ relative humidity. For each experiment conducted, the aphids used were all of the same age. For breeding synchronization, apterous females were deposited per plant. Twenty-four hours later, these females were removed, whereas the larvae generated remained on the pepper plant. After 10 days, this cohort of $24 \mathrm{~h}$ gave the necessary adult individuals to be used in the experiments.

\section{Plant material}

Five clones of rosemary (Rosmarinus officinalis L.) were propagated by cuttings from specimens collected from plots from CRIEPPAM (Centre Régionalisé Interprofessionnel d'Expérimentation en Plantes à Parfum, Aromatiques et Médicinales, France). The clones considered in the present study were: Esselte (E), Nonza (N), Pigette (P), Sudbery Blue (SB) and Voltz Splindler (VS). These clones were selected based on preliminary results that reported the existence of variability in the chemical profile of their essential oils (L. Gomez et al., unpublished data). The five clones were propagated at the same moment and cultivated in a greenhouse of INRA Avignon under controlled conditions (temperature of $20 \pm 5{ }^{\circ} \mathrm{C}$ and $60-70 \%$ relative humidity). The cultivated clones did not receive any fertilization or phytosanitary treatments. The irrigation was carried out with a drip system to homogenize the production conditions. For all of the experiments carried out, the plants were used at the same vegetative stage (6-8 months old). The pepper plants (Capsicum annuum L., var. Yolo Wonder) used for the M. persicae mass rearing were 6 weeks old (with 5-6 developed leaves) and were obtained by sowing in another glass greenhouse to avoid any interaction with the rosemary clones. All of the plants were cultivated in 1-L pots filled with peat.

\section{Volatile profile characterization}

The profile of the VOCs from each clone was analyzed by HS-headspace solid phase micro-extraction (SPME) and GC-MS. For the analyses, 15 plants were used per clone, divided into three groups of five plants each. On the day before sampling, the plants were placed under the experimental conditions: temperature of $22^{\circ} \mathrm{C} \pm 1{ }^{\circ} \mathrm{C}$ and $60 \pm 5 \%$ relative humidity. The plants were watered and the pots were wrapped in aluminium foil to prevent sample pollution by VOCs from the culture substrate and plastic pot. For each analysis, five plants were carefully introduced without touching the foliage inside a parallelepiped-shaped Plexiglas chamber (width $40 \mathrm{~cm}$, length $40 \mathrm{~cm}$, height $50 \mathrm{~cm}$ ) (Fig. 1). To homogenize the atmosphere inside the Plexiglas chamber during sampling and to promote 


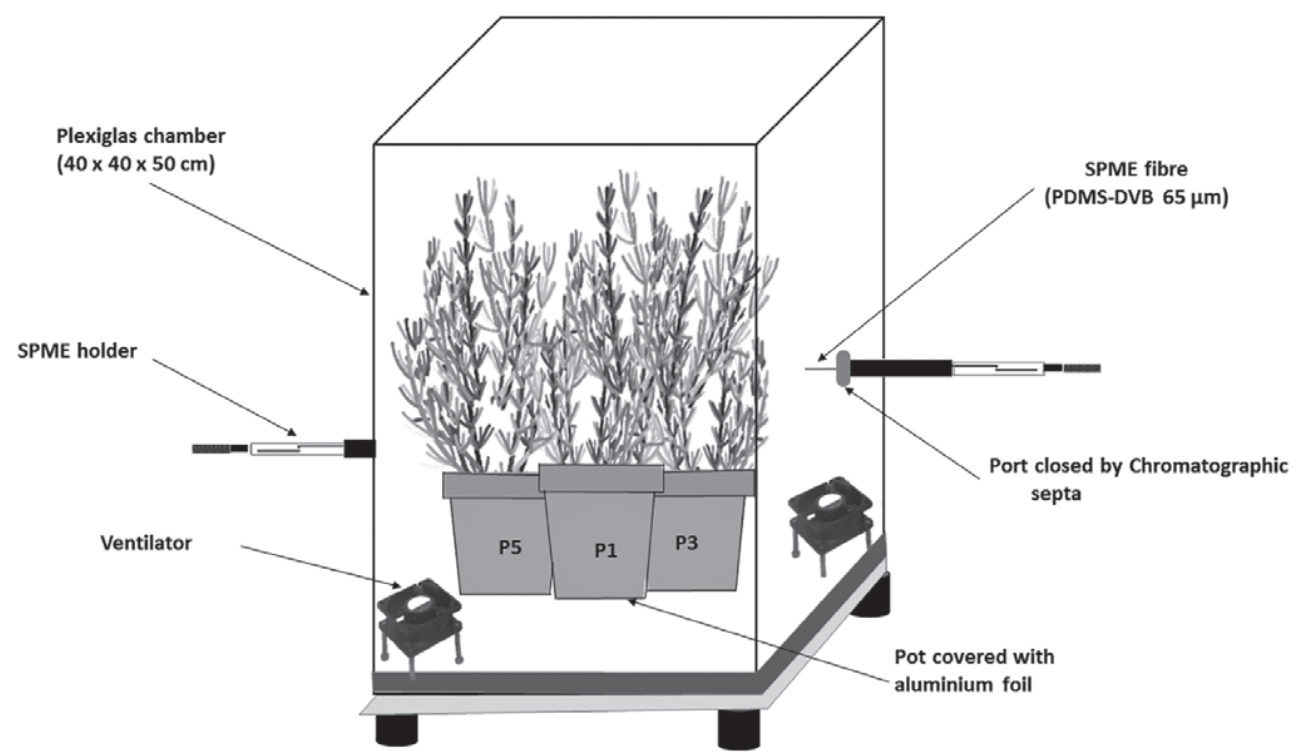

Figure 1 Device for static sampling of volatile organic compounds (VOCs) emitted from rosemary clones using the headspace solid phase micro-extraction technique.

the adsorption of the VOCs on the SPME fibre, two ventilator fans were installed at the base.

After $10 \mathrm{~min}$ of stabilization, two polydimethylsiloxane/ divinylbenzene SPME fibres (PDMS-DVB, $65 \mu \mathrm{m}$; Supelco, Bellefonte, Pennsylvania) were introduced simultaneously through two septa positioned on the walls. After an exposure time of $5 \mathrm{~min}$, the SPME fibres were removed together with the sampled plants. This experiment was conducted at $10.00 \mathrm{~h}$, and the other two groups of plants were analyzed at $13.00 \mathrm{~h}$ and $16.00 \mathrm{~h}$, with a total of six samples per clone ( 2 fibres $\times 3$ sampling moments), reporting an average profile throughout the day. Before each SPME analysis, the air inside the chamber was renewed with a vacuum cleaner and the cage was cleaned with $70 \%$ ethanol and distilled water to avoid contamination. The SPME analyses were carried out at a rate of one clone per day.

The VOC samples were rapidly analyzed by GC-MS (Trace-ISQ, single quadrupole; Thermo Scientific, Austin, Texas) equipped with an apolar capillary column TR-5MS (Thermo Scientific) $(20 \mathrm{~m} ; 0.1 \mathrm{~mm}$ inner diameter; $0.1 \mu \mathrm{m}$ film thickness). The carrier gas was helium at a constant flow of $0.4 \mathrm{~mL} \mathrm{~min}^{-1}$. The desorption of the SPME fibre was performed during $2 \mathrm{~min}$ in the injector at $250^{\circ} \mathrm{C}$ in splitless mode. The oven temperature was set at $40^{\circ} \mathrm{C}$ for 2 min after desorption, followed by an increase of $20^{\circ} \mathrm{C} \mathrm{min}^{-1}$ up to $100^{\circ} \mathrm{C}$, then $5{ }^{\circ} \mathrm{C}$ $\min ^{-1}$ up to $160^{\circ} \mathrm{C}$ and, finally, $30^{\circ} \mathrm{C} \min ^{-1}$ up to $300^{\circ} \mathrm{C}$. The mass spectra were recorded in electron impact mode with an ionization energy of $70 \mathrm{eV}$ in the range $\mathrm{m} / \mathrm{z} 35-450$.

The VOCs were identified by comparing their mass spectra with the spectra of the NIST11 library (National Institute of Standards and Technology, Gaithersburg, Maryland). The retention times of the compounds to be identified were compared with those obtained from commercial standards. The quantification was carried out by manual integration of the peaks obtained using XCALIBUR (Thermo Scientific).

\section{Standards and reagents}

The VOCs identified in the obtained olfactory mixtures produced by the rosemary clones were supplied by Sigma-Aldrich (France). The standards were purchased to individually test their effect on green peach aphids. The standards obtained were (with the respective standard purity represented in brackets): bornyl acetate (95\%), borneol (99\%), camphene (95\%), camphor (96\%), eucalyptol (99\%), geranyl acetone (97\%), limonene (97\%), linalol (97\%), terpinene-4-ol (95\%), terpinolene $(90 \%)$, verbenone (93\%), $\alpha$-pinene $(98 \%), \alpha$-terpineol $(96 \%)$ and $\gamma$-terpinene (97\%). (E)- $\beta$-farnesene $(93 \%)$ was used as a positive control. Only $\beta$-terpineol was not available for purchase. Each compound was tested at a concentration of $1 \%$ diluted in ethanol $(\mathrm{v} / \mathrm{v} ; \mathrm{m} / \mathrm{v}$ in the case of camphor). The concentration used makes it possible to obtain a peak area similar to the sum of the peak areas emitted by a whole plant to avoid saturation of the olfactometer.

\section{Olfactometer bioassays with M. persicae}

The dual-choice olfactometer used (Eigenbrode et al., 2002; Ameline et al., 2007; Alvarez et al., 2007) is a device with a static atmosphere, consisting of two overlapping containers of different sizes, with facing openings provided with a polyethylene grid (0.09 $\mathrm{mm}^{2}$ mesh) (Fig. 2). The upper container is a cylindrical Plexiglas arena (diameter $14 \mathrm{~cm}$, height $5 \mathrm{~cm}$ ) hermetically subdivided into two equal chambers. Each side of this container is pierced to allow the introduction of a leaf or plant part through a 5-mm opening. To prevent mechanical injuries, each opening is protected with foam. The lower container (diameter $9 \mathrm{~cm}$, height $2.5 \mathrm{~cm}$ ), where aphids are placed, is positioned below the arena polyethylene grid.

All of the bioassays were performed in a ventilated room, maintained at $22 \pm 1{ }^{\circ} \mathrm{C}$ and relative humidity of $60 \pm 5 \%$. The 


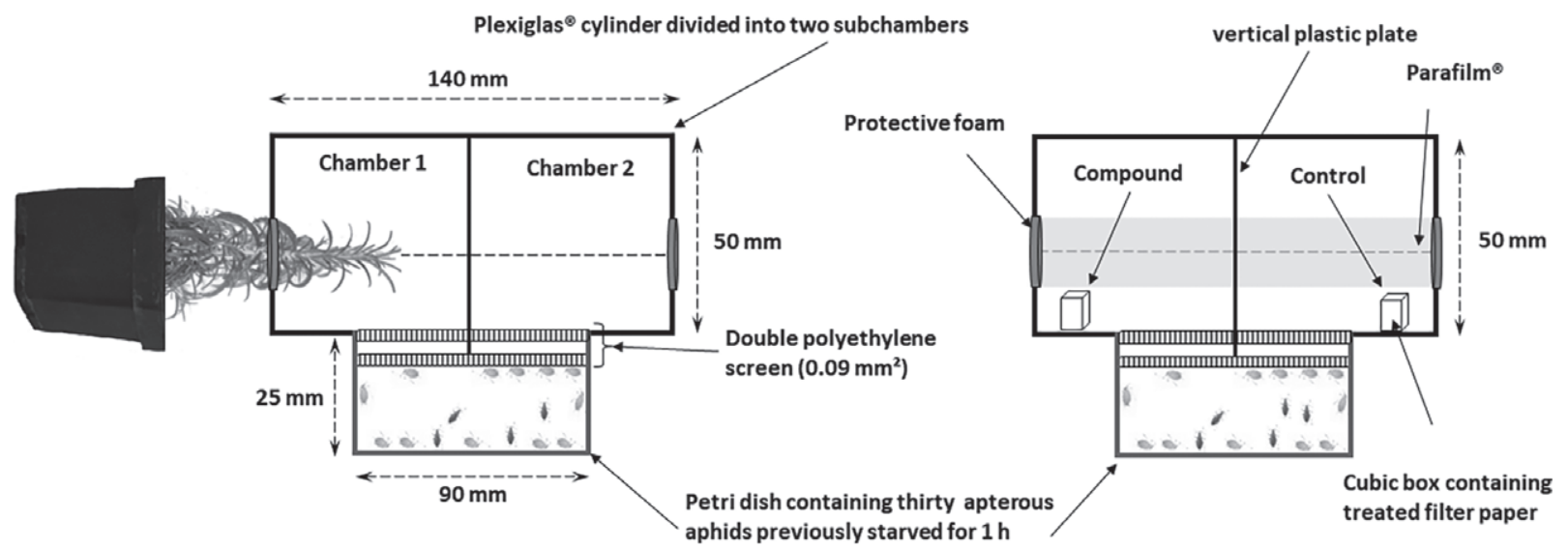

Figure 2 Dual-choice olfactometer used for the olfactometry bioassays conducted with Myzus persicae: (A) rosemary versus control (without plant); (B) $10 \mu \mathrm{L}$ of volatile compound (1\%) versus control ( $10 \mu \mathrm{L}$ of ethanol). An aphid is considered as a responder if it is positioned on the grid under one of the two chambers.

bioassays were conducted in darkness to avoid any visual cue that could influence the orientation of aphids. One hour before starting the bioassays, the plants were placed in the room. Thirty apterous females from a cohort of 10 days were placed in the lower container with a brush soaked in demineralized water. A fasting period of $1 \mathrm{~h}$ in the dark allowed aphids to equalize their physiological state. A fragment of rosemary plant was introduced into one upper chamber versus control (empty chamber). To test the VOCs, $10 \mu \mathrm{L}$ of the VOC $(1 \%$ solution in ethanol) was deposited on filter paper $(2 \times 2 \mathrm{~cm})$ in a cubic box $(2.1 \times 2.1 \mathrm{~cm})$, which was then fixed in a chamber from the upper arena. A second paper with $10 \mu \mathrm{L}$ of ethanol was placed in the second chamber, serving as a control. The papers were left to dry for $5 \mathrm{~min}$. The upper arena was then closed and sealed with Parafilm ${ }^{\circledR}$ to seal the olfactometer. The lower container, with the aphids homogeneously distributed, was immediately placed under the upper container. Aphids underwent negative geotaxis and climbed onto the upper grid (Eigenbrode et al., 2002) where they positioned themselves in accordance with their olfactory orientation under one of the two upper chambers. Each bioassay lasted for $1 \mathrm{~h}$. After this period, the upper container was removed and the lower container was photographed to record the distribution of the aphids. An aphid was considered as a 'responder' when it was placed on the grid and as a 'nonresponder' when it was placed in the edges of the container or when it was not in the grid. In each bioassay, only the responders were counted considering the side of the upper chamber where they were positioned. Each choice hypothesis was tested eight times in eight olfactometers used in parallel. Per treatment and hypothesis to be tested, 240 aphids were studied ( 8 olfactometers $\times 30$ apterous females). To avoid the risk of contamination, a single clone or VOC was tested per day and the entire structure was cleaned with $70 \%$ ethanol and distilled water.

Finally, two complementary assays were carried out (blank versus blank and solvent versus solvent) to ensure a lack of experimental bias. An assay with pepper versus blank allowed the characterization of the behaviour of $M$. persicae insects in the presence of the host plant (pepper).

\section{Statistical analysis}

Statistical analyses were performed using XLSTAT, version 2016.02 (Addinsoft, France). The number of nonresponders between the different treatments (insects that did not orient to any chamber of the olfactometer were designated as nonresponders) was compared using the nonparametric Kruskall-Wallis test. In the case of significant differences, the number of nonresponders was compared using Tukey's test $(\alpha=0.05)$. For each treatment conducted, the distribution of responders on each chamber of the olfactometer was analyzed using a Wilcoxon test for paired samples. The significance level was $\alpha=0.05$. To compare the differences in emissions of VOCs of different rosemary clones, Tukey's test with a 95\% confidence interval was performed. A principal component analysis (PCA) was also carried out to show the variability of the VOCs between the different clones.

\section{Results}

\section{Analysis of the VOC profiles from the rosemary clones}

The VOC profiles of the five different clones of rosemary (Esselte, Nonza, Pigette, Sudbery Blue and Voltz Splindler) allowed the identification of 15 compounds. From these 15 compounds, 11 were present in the five clones, whereas linalol, $\alpha$-terpineol and verbenone were absent from the Voltz Splindler clone. Other VOCs, namely $(E)$ - $\beta$-terpineol and terpinolene, were also absent from the volatile profile of Esselte (Table 1). Analysis of VOC profiles revealed that VOC emission was highly dependent on the clone. From these, there were five major components (Table 1) in the different clones: $\alpha$-pinene, eucalyptol (except for Nonza), camphor, borneol and bornyl acetate. Bornyl acetate was the main VOC in Nonza, Sudbery Blue and Voltz Splindler, and camphor was the main VOC in Pigette and Esselte (Table 1). The proportion of $\alpha$-pinene was homogeneous between the clones that were analyzed, varying on average between $16 \%$ and $26 \%$ (Pigette and Esselte, 


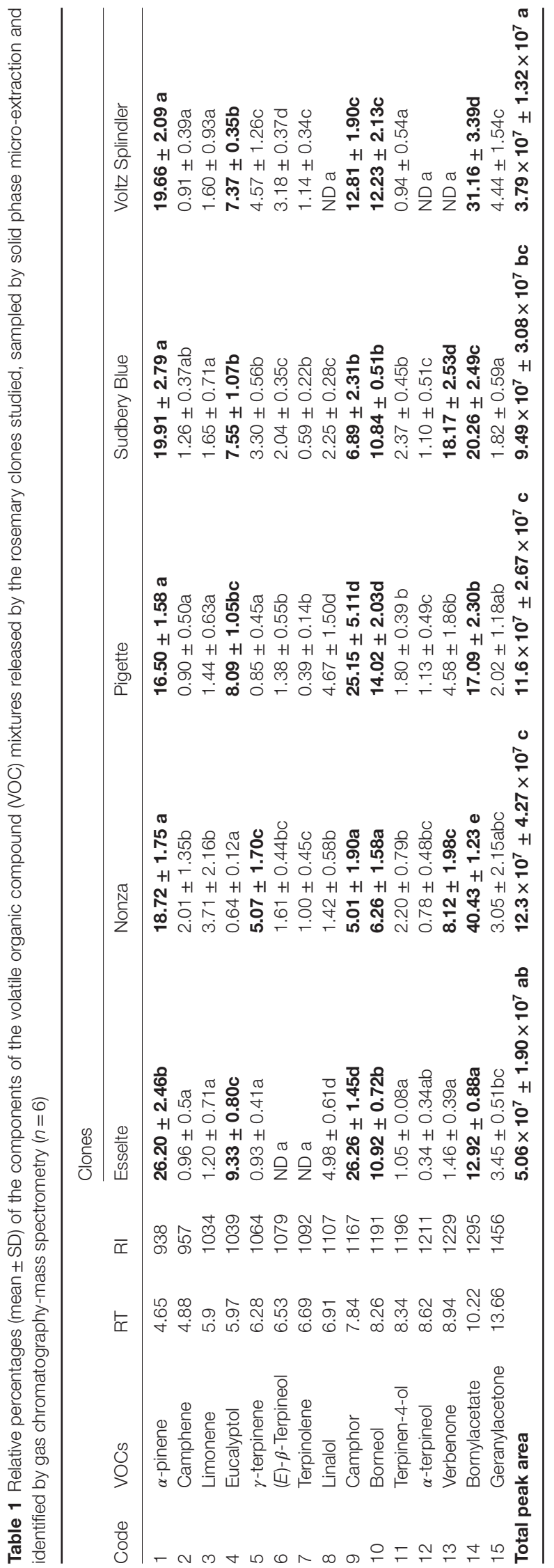

respectively). The same observation was made for eucalyptol with a relative percentage below $10 \%$, whereas borneol represented between $6 \%$ (Nonza) and 14\% (Pigette) of the total VOCs emitted. Two other VOCs showed a higher variability among rosemary clones: camphor ranged from $5 \%$ (Nonza) to $25 \%$ (Pigette), whereas bornyl acetate varied from $13 \%$ (Esselte) to $40 \%$ (Nonza). It was also confirmed that verbenone is especially important in Sudbery Blue, at 18\% (Table 1).

The PCA obtained using the VOCs of the five rosemary clones (Fig. 3) showed that clones formed distinct groups on the first plane of the PCA. Each clone was characterized by a specific profile, which allowed observation of the existence of marked chemical variability, thus allowing separation of the clone on the PCA. The first two dimensions (F1 and F2) of the PCA explained $61.5 \%$ of the total variability of the data $(41.84 \%$ for the F1 axis and $19.74 \%$ for the F2 axis). The first axis, F1, allowed separation of clones richer in camphor (9), eucalyptol (4) and linalol (8), such as Esselte and Pigette, located on the left side of the PCA, from clones richer in $\gamma$-terpinene (5), bornyl acetate (14) and terpinolene (7), namely Nonza, Sudbery Blue and Voltz Splindler.

The second dimension of the PCA, F2, allowed distinction of the clones richer in $\alpha$-terpineol (12), terpinene-4-ol (11) and verbenone (13), namely Pigette, Sudbery Blue and Nonza, as represented in the positive region of $\mathrm{F} 2$, from those clones represented in the negative region of $\mathrm{F} 2$, characterized for being richer in geranyl acetone (15), namely Esselte and Voltz Splindler (Fig. 3).

\section{Orientation of Myzus persicae under the influence of olfactory bouquets from rosemary clones}

The percentage of aphids classified as nonresponders ranged from $27.5 \%$ to $44.5 \%$. Nevertheless, these results were not statistically different among the different clones analyzed (Kruskall-Wallis: $K=8.43 ; P=0.208$ ). Figure 4 shows the distribution of aphid responders in the presence of a rosemary clone in one chamber of the olfactometer against control in the other chamber (empty chamber). The results of the blank versus blank (Wilcoxon: $P=0.83$ ) and the pepper versus blank (Wilcoxon: $P=1$ ) assays showed no significant differences in the choice of aphids between the two olfactometer chambers. In the tests carried out with rosemary clones, aphids tended to choose the blank compared with those with companion plants. However, only the Voltz Splindler clone reported a statistically significant effect on the orientation of aphids, at $37.34 \%$ $(P=0.014)$. The remaining clones did not result in a significant change in the orientation of aphids: Nonza $45.98 \%$ (Wilcoxon: $P=0.17$ ); Esselte $45.39 \%$ (Wilcoxon: $P=0.30$ ); Sudbery Blue 42.41\% (Wilcoxon: $P=0.29$ ); and Pigette $42.86 \%$ (Wilcoxon: $P=0.30)$.

\section{Effect of individual VOCs on the orientation of M. persicae}

In the assays of individual VOCs, the percentage of nonresponders ranged from $24.2 \%$ to $46.7 \%$. Although there was a significant difference in the number of nonresponders according to the VOC (Kruskall-Wallis: $K=41.19 ; P=0.0002$ ), none differed significantly from the negative and positive controls: blank and (E)- $\beta$-farnesene, respectively (Fig. 5). Nevertheless, 
(A)

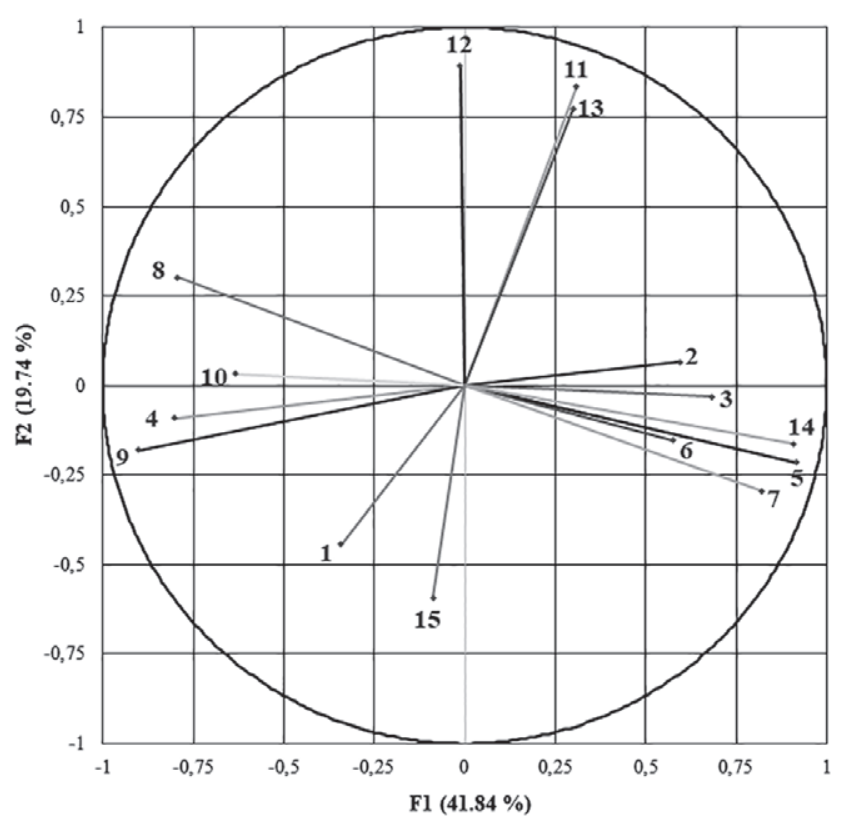

(B)

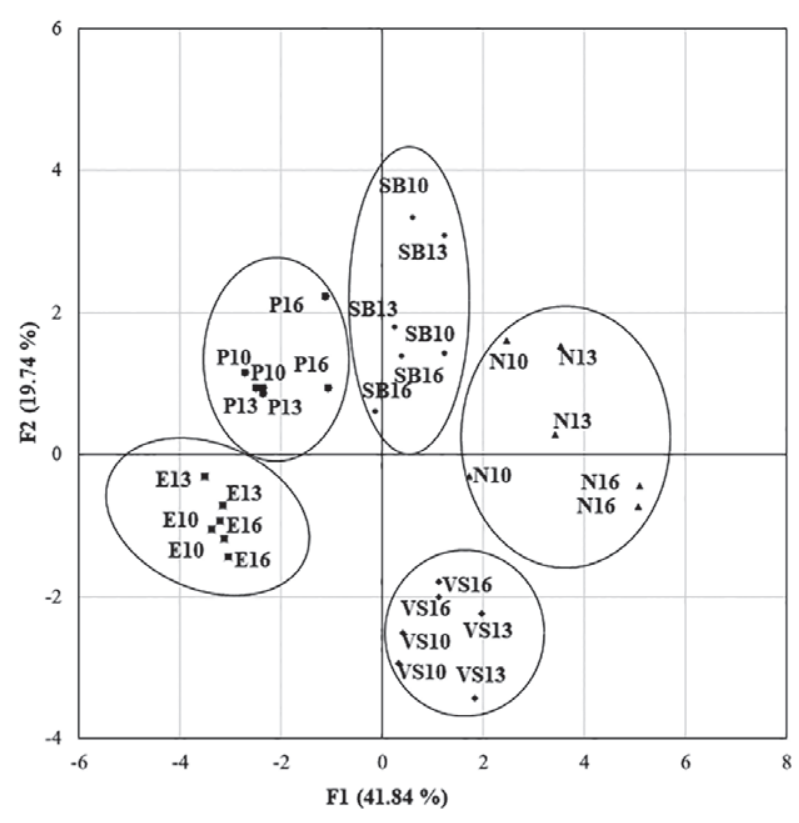

Figure 3 Principal component analysis obtained from the relative percentages of volatile organic compounds (VOCs) from rosemary clones: (A) correlations circle of the VOCs variables on the two axes F1 and F2; (B) projection of the 30 samplings of VOCs from the five rosemary clones during three periods $(10.00 \mathrm{~h}, 13.00 \mathrm{~h}$ and $16.00 \mathrm{~h}$ ) with two solid phase micro-extraction fibres on the two axes F1 and F2. The identity of the VOCs is shown in Table 1. E, Esselte; N, Nonza; P, Pigette; SB, Sudbery Blue; VS, Voltz Splindler.

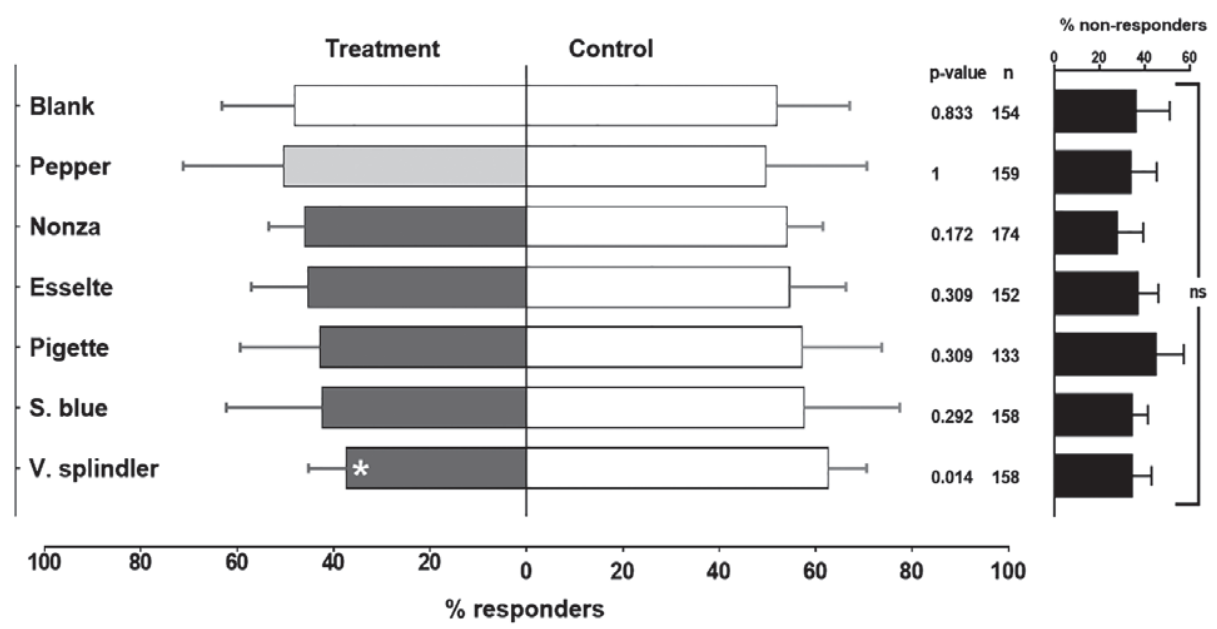

Figure 4 Myzus persicae responder orientation in the presence of a rosemary clone in one chamber of the olfactometer (grey bars) and control in the other one (empty chamber; white bars). Light grey bars represent pepper. The asterisk ( ${ }^{*}$ ) indicates a significant difference (Wilcoxon test) with $P<0.05$; $n$ represents the total number of responders and black bars in the histogram on the right represent the percentages of nonresponders for 240 aphids tested in each treatment; ns, no significant differences (Kruskall-Wallis test at $\alpha=0.05$ ); error bars indicate the SD.

the olfactory behaviour of $M$. persicae differed according to the VOC assayed. The positive control, $(E)-\beta$-farnesene, clearly induced the orientation of aphids towards blank: $(E)$ - $\beta$-farnesene 20.99\% ( $P=0.014)$. Only five VOCs elicited a significant repellent effect compared with blank: bornyl acetate $39.74 \%$ (Wilcoxon: $P=0.035$ ); camphor $37.43 \%$ (Wilcoxon: $P=0.041$ ); $\alpha$-terpineol $36.71 \%$ (Wilcoxon: $P=0.019$ ); terpinene-4-ol $36.25 \%$ (Wilcoxon: $P=0.014$ ); and geranyl acetone $33.77 \%$ (Wilcoxon: $P=0.022$ ).

\section{Discussion}

The volatile profile of our five rosemary clones has almost the same composition in terms of VOCs, although in different concentrations and proportions. All were previously identified in studies with whole plants (Zhang et al., 2014a; Ben Issa et al., 2016) or in rosemary essential oil (Hori \& Komatsu, 1997; Hori, 1998; Isman et al., 2008; Pausas et al., 2015). These results confirm that genetic variability influences VOC production in a 


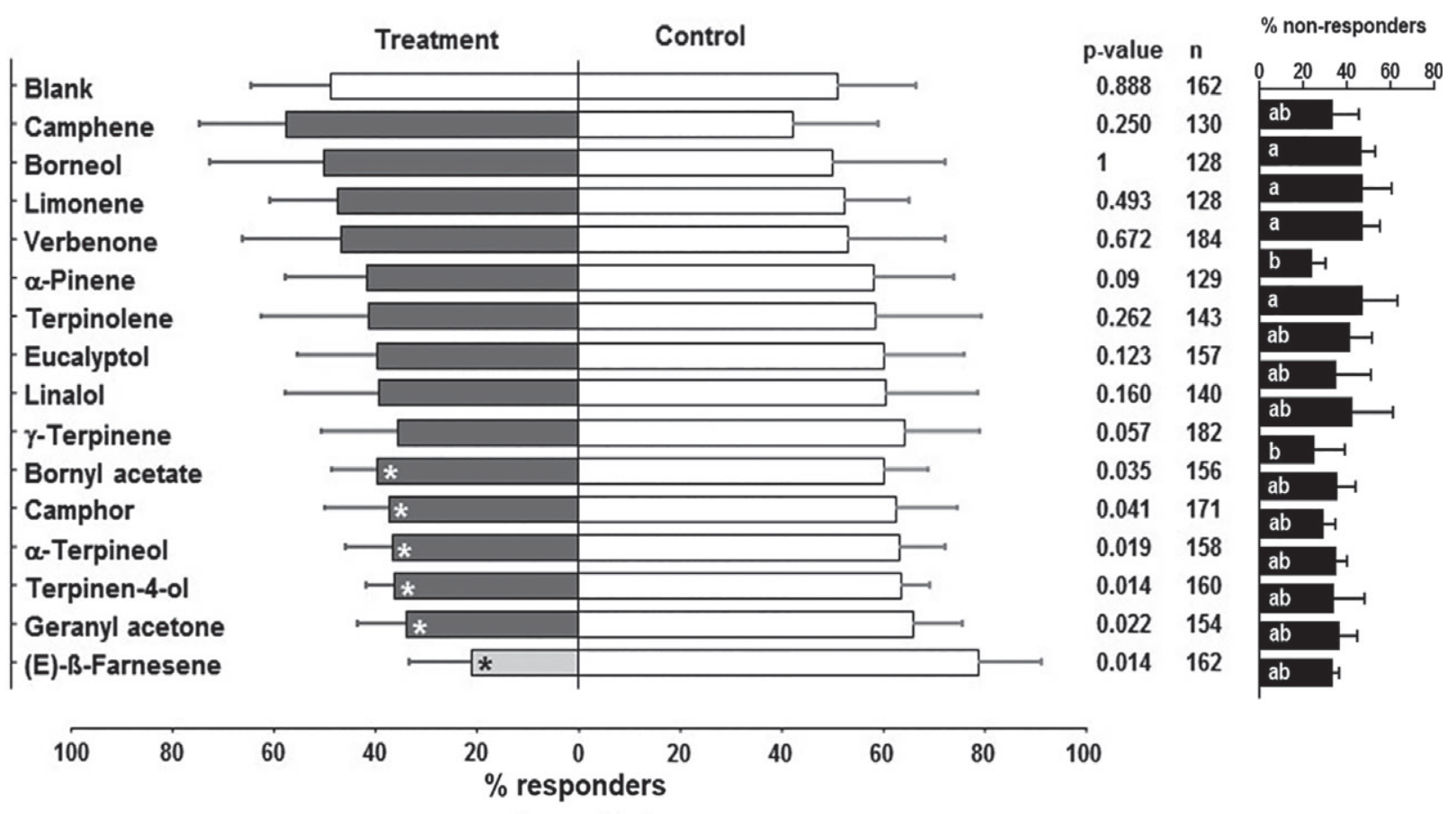

Figure 5 Myzus persicae responders' orientation in the presence of a volatile compound (10 $\mu \mathrm{L}$ at $1 \%)$ in one chamber of the olfactometer (grey bars) and control in the other one (10 $\mu \mathrm{L}$ of ethanol; white bars). Light grey bars represent positive control ((E)- $\beta$-farnesene). The asterisk (*) indicates a significant difference (Wilcoxon test) with $P<0.05 ; n$ represents the total number of responders and black bars in the histogram on the right represent the percentages of nonresponders for 240 aphids tested for each treatment; values presented with the same lowercase letter are not significantly different (Tukey's test at $\alpha=0.05)$; error bars indicate the SD.

quantitative and qualitative way (Tholl \& Lee, 2011; Schröder et al., 2015). Although VOC production varies throughout the day, overall, their proportion in the olfactory bouquet is relatively stable. This gives the olfactory bouquet, considered as a whole, a chemical signature that separates genotypes (see PCA in Fig. 3). Nevertheless, environmental factors, phenology and plant cultivation also influence the characteristics of the VOC production (Pichersky \& Gershenzon, 2002).

One reason for interest in rosemary is its presumed potential repellency for pests (Koschier \& Sedy, 2003; Miresmailli et al., 2006; Zhang \& Chen, 2015; Zhang et al., 2014a), particularly towards the green aphid (Hori, 1998; Ben Issa et al., 2016, $2017 \mathrm{~b}$ ). The arena olfactometer, similar to most of the olfactometers described previously (Hori, 1998; Wang et al., 2015), allows for testing of choice or preference bioassays, which are used to estimate the repellent power. The fact that aphids were distributed homogeneously during the blank tests showed the absence of a preference for a chamber and thus of bias within the arena device. Similarly, bioassays carried out with pepper showed that this host plant does not emit an attractive olfactory volatile mixture for $M$. persicae. (E)- $\beta$-farnesene (the aphid alarm pheromone) (Francis et al., 2004), which was used as a positive control and is highly repulsive, confirmed the functionality of the olfactometer. Thus, when the aphids avoid the side with a volatile, it is repulsive. In this case, in the bioassays performed with five rosemary clones, all of the clones reported repulsive capacities towards $M$. persicae, although only the effect of Voltz Splindler was statistically significant $(P<0.05 \%)$. The same repellent effect has already been reported for the Pyramidal clone (Ben Issa et al., 2016). Therefore, the rosemary genetics may explain the observed differences in aphid behaviour. This is consistent with several studies reporting that the repulsion (or attraction) of the aphid differs according to the VOC profile produced by different cultivars (Storer \& van Emden, 1995; Wang et al., 2009; da Costa et al., 2010; Schröder et al., 2015). This evidence is also valid for other pests sensitive to the olfactory environment, such as thrips Frankliniella occidentalis (Pergande), (Thysanoptera: Thripidae) in rosebushes (Gaum et al., 1994) and the whitefly Trialeurodes vaporariorum (Westwood) (Hemiptera: Aleyrodidae) in tomatoes or eggplants (Darshanee et al., 2017). In this sense, genetic variability should be taken into consideration when choosing companion plants and can comprise a potential lever for improving companion plant effectiveness. It should be emphasized that the absence of a significant repellent effect does not prevent a clone from having an impact on the fecundity of the aphid negatively, as reported by Ben Issa et al. (2017b). The results of the present study support the ability of rosemary terpenes to affect the performance of $M$. persicae (Hori, 1998, 1999a; Ben Issa et al., 2016, 2017b).

The olfactometer bioassays conducted with individual VOCs emitted from rosemary were performed to identify their potential effect with respect to the behavioural choice of the aphids, aiming to better understand the mode of action of the olfactory bouquet. The efficacy of the olfactory bouquet may result from the individual effect of certain VOCs on the behaviour of the aphid or from an effect resulting from the relative proportion in the blend of certain VOCs via an interactive and synergetic action (Zhang et al., 2014a). Regarding the rosemary VOCs 
tested at the same concentration, not all elicited a significant effect on the behavioural response and choice of aphids. From the VOCs emitted from rosemary, only five showed a significant repulsive effect on aphids, namely bornyl acetate, camphor, $\alpha$-terpineol, terpinene and geranyl acetone. These terpenic compounds were already reported to be involved in the ability of rosemary plants to reduce the performance of M. persicae (Hori, 1998, 1999a) and the behaviour of other insects. For example, camphor is a proven repellent not only for M. persicae (Hori, 1998), but also for the onion aphid Neotoxoptera formosana (Takahashi) (Homoptera: Aphididae) (Hori \& Komatsu, 1997) and mosquitoes (Hwang et al., 1985). Camphor also induces an anti-appetizing effect on $M$. persicae (González-Coloma et al., 2011) and a toxic effect on the lesser grain borer Rhyzopertha dominica (Fabricius) (Coleoptera: Bostrichidae) (Rozman et al., 2007) and also on the rice weevil Sitophilus oryzae (Linnaeus) (Coleoptera: Curculionidae) (Abdelgaleil et al., 2009). Bornyl acetate has a repellent effect on mosquitoes and Coleoptera species (Hwang et al., 1985; Park et al., 2003; Rozman et al., 2007) and an anti-appetising effect against the bird cherry-oat aphid Rhopalosiphum padi (Linnaeus) (Hemiptera: Aphididae) (González-Coloma et al., 2011). Terpinene-4-ol is a toxic VOC and has insecticidal activity against several insects (Isman, 2004; Abbassy et al., 2009). The $\alpha$-terpineol has a repellent activity towards M. persicae (Hori, 1998). Geranyl acetone demonstrated a highly repellent activity against the green pea aphid Acyrthosiphon pisum (Harris) (Hemiptera: Aphididae) (Zhang et al., 2017) and Bemisia tabaci (Gennadius) (Hemiptera: Aleyrodidae) (Deletre et al., 2015).

According to the results of the present study, the remaining VOCs emitted from rosemary ( $\alpha$-pinene, camphene, limonene, eucalyptol, $\gamma$-terpinene, terpinolene, linalol, borneol and verbenone) do not cause a significant repellent effect on $M$. persicae. The lack of a repellent effect on $M$. persicae was also observed by Bruce et al. (2005) for linalol and by Hori (1998) for $\alpha$-pinene, camphene, eucalyptol and borneol. Nevertheless, several studies demonstrated the effect of these VOCs on the behaviour of aphids and other insects (Chapman et al., 1981; Hori \& Komatsu, 1997; Hori, 1998; Tomova et al., 2005; Rozman et al., 2007; Abdelgaleil et al., 2009; Halbert et al., 2009; Webster et al., 2010; Zhang et al., 2014b; Lamy et al., 2016; Jiang et al., 2016). Such contradictions are not necessarily surprising and testify the difficulty of making comparisons without considering the experimental conditions. The first cause of variability is undoubtedly the concentration of the VOCs tested (Foster et al., 2007). It is also possible that these compounds are more repulsive in combination and in a synergetic action with other VOCs (Deletre et al., 2016). Among the five repellent VOCs, bornyl acetate is the major component (35\%) in the olfactory bouquet of the rosemary Voltz Splindler clone. Nevertheless, the same VOC was present at a relative proportion of $40 \%$ in the least repellent clone, Nonza. Therefore, this major VOC cannot alone explain the repellent action of Voltz Splindler on $M$. persicae. Consequently, we can hypothesize that the repellency level does not result from the accumulation of individual repulsive effects of the VOCs. For example, the Nonza clone accumulates $50 \%$ of repellent VOCs versus $48 \%$ in Voltz Splindler. These results suggest that the repulsion of a companion plant is more related to a blend of VOCs (with a significant synergetic effect), as noted by Bruce and Pickett (2011), than the sole action of a specific repellent VOC. The results obtained in the PCA (Fig. 3) point toward the same direction, with it being difficult to establish a link between the repulsive efficacy of Voltz Splindler and the repellency of each VOC emitted. Repulsion may also be associated with the presence of minor components that are sometimes difficult to detect (McCormick et al., 2014). Bruce et al. (2005) reported that the sesquiterpene (+)-bicyclogermacrene inhibited the effect of $(E)$ - $\beta$-farnesene on $M$. persicae and also that (-)-germacrene D resulted in the same effect in the pea aphid A. pisum. Dawson et al. (1984) showed that, depending on the concentration of VOCs in the olfactory bouquet, $\beta$-caryophyllene may inhibit the aphid response to the aphid alarm pheromone $(E)$ - $\beta$-farnesene. Also, the relative proportion of each VOC in the volatile profile perceived by the aphid plays an important role in its olfactory response. Some specific ratios may elicit a maximum repelling action (Zhang et al., 2014a).

In this first comparative study, we noted the limitations of testing the VOCs individually at the same concentration (1\%), which does not correspond to the relative proportion of each VOC in the olfactory bouquet of rosemary. A slight change in the concentration or absence of a designated VOC in the olfactory bouquet can disrupt the repellent action reported previously (Rajabaskar et al., 2013; Zhang et al., 2014a). Additional studies that test a range of concentrations and establish a dose-response curve for each VOC would be relevant. The relative proportion of VOCs perceived by the aphid also appears to affect its olfactory response (Zhang et al., 2014a). A complementary approach might consist of determining whether VOC associations retrieve higher or lesser repellent properties, as reported by Webster et al. (2010). Finally, we could attempt to simulate the volatile bouquet emitted from rosemary, then create variations by removing one or more VOCs from the bouquet with the aim of isolating the most effective odour combination (Bruce \& Pickett, 2011).

\section{Conclusions}

In conclusion, the present study demonstrates the importance of the genetic variability of rosemary clones with respect to their level of repulsion for $M$. persicae. The five clones studied emit, with few exceptions, the same VOCs but in different concentrations and relative proportions. Most of the VOCs identified are terpenic compounds and, among them, five significantly repel aphids. The Voltz Splindler clone, which is the only to demonstrate real repellent properties, has four of the five VOCs that are themselves repellent in the individual assays. Nonza, the least repellent clone, emits these five VOCs in higher quantities and proportions compared with Voltz Splindler. Such results confirm that the effectiveness of an olfactory bouquet is related more to a blend of compounds and the synergetic actions between than to the sum of the effects of individual VOCs with repellent properties. Thus, the production of a specific repulsive VOC cannot be used as a reliable marker of the effectiveness of a companion plant and therefore promoting its emission by genetic selection or culture is not sufficient. On the basis of the results obtained in the present study, we must therefore assess and integrate the beneficial or harmful interactions within the olfactory bouquet emitted from the rosemary clones. Such an aspect should guide our approach with respect to optimizing the repulsive efficiency 
of companion plants of interest, namely Voltz Splindler, by testing, for example, artificial combinations of VOCs.

\section{Acknowledgements}

We thank the CRIEPPAM (Centre Régionalisé Interprofessionnel d'Expérimentation en Plantes à Parfum, Aromatiques et Médicinales) for supplying rosemary clones. We also thank Michel Pradier for the maintenance of plants and Julie Courtois for breeding the aphids. We are in debt to Refka Ben Issa and Marie-Hélène Sauge for their advice. Tarek Dardouri is funded by a scholarship from the Tunisian Ministry of Higher Education and Scientific Research. This manuscript is part of the $\mathrm{PhD}$ thesis of Tarek Dardouri.

\section{References}

Abbassy, M.A., Abdelgaleil, S.A.M. \& Rabie, R.Y.A. (2009) Insecticidal and synergistic effects of Majorana hortensis essential oil and some of its major constituents. Entomologia Experimentalis et Applicata, 131, $225-232$.

Abdelgaleil, S.A., Mohamed, M.I., Badawy, M.E. \& El-arami, S.A. (2009) Fumigant and contact toxicities of monoterpenes to Sitophilus oryzae (L.) and Tribolium castaneum (Herbst) and their inhibitory effects on acetylcholinesterase activity. Journal of Chemical Ecology, 35, 518-525.

Alvarez, A.E., Garzo, E., Verbeek, M., Vosman, B., Dicke, M. \& Tjallingii, W.F. (2007) Infection of potato plants with potato leafroll virus changes attraction and feeding behaviour of Myzus persicae. Entomologia Experimentalis et Applicata, 125, 135-144.

Ameline, A., Couty, A., Dugravot, S., Campan, E., Dubois, F. \& Giordanengo, P. (2007) Immediate alteration of Macrosiphum euphorbiae host plant-selection behaviour after biotic and abiotic damage inflicted to potato plants. Entomologia Experimentalis et Applicata, 123, 129-137.

Angioni, A., Barra, A., Cereti, E. et al. (2004) Chemical composition, plant genetic differences, antimicrobial and antifungal activity investigation of the essential oil of Rosmarinus officinalis L. J Agriculture and Food Chemistry, 52, 3530-3535.

Bass, C., Puinean, A.M., Zimmer, C.T. et al. (2014) The evolution of insecticide resistance in the peach potato aphid, Myzus persicae. Insect Biochemistry and Molecular Biology, 51, 41-51.

Ben Issa, R., Gautier, H., Costagliola, G. \& Gomez, L. (2016) Which companion plants affect the performance of green peach aphid on host plants? Testing of 12 candidate plants under laboratory conditions. Entomologia Experimentalis et Applicata, 160, 164-178.

Ben Issa, R., Gomez, L. \& Gautier, H. (2017a) Companion plants for aphid pest management. Insects, 8, 112-131.

Ben Issa, R., Gautier, H. \& Gomez, L. (2017b) Influence of neighbouring companion plants on the performance of aphid populations on sweet pepper plants under greenhouse conditions. Agricultural and Forest Entomology, 19, 181-191.

Blackman, R.L. \& Eastop, V.F. (2000) Aphids on the World's Crop: And Identification and Information Guide. John Wiley \& Sons Ltd, U.K.

Bruce, T.J. \& Pickett, J.A. (2011) Perception of plant volatile blends by herbivorous insects-finding the right mix. Phytochemistry, 72, $1605-1611$.

Bruce, T.J.A., Birkett, M.A., Blande, J. et al. (2005) Response of economically important aphids to components of Hemizygia petiolata essential oil. Pest Management Science, 61, 1115-1121.

Castro, A.M., Tapias, J., Ortiz, A., Benavides, P. \& Góngora, C.E. (2017) Identification of attractant and repellent plants to coffee berry borer,
Hypothenemus hampei. Entomologia Experimentalis et Applicata, 164, 120-130.

Chapman, R.F., Bernays, E.A. \& Simpson, S.J. (1981) Attraction and repulsion of the aphid, Cavariella aegopodii, by plant odors. Journal of Chemical Ecology, 7, 881-888.

Chopa, C.S. \& Descamps, L.R. (2012) Composition and biological activity of essential oils against Metopolophium dirhodum (Hemiptera: Aphididae) cereal crop pest. Pest Management Science, 68, $1492-1500$

da Costa, J.G., Pires, E.V., Riffel, A., Birkett, M.A., Bleicher, E. \& Sant'Ana, A.E.G. (2010) Differential preference of Capsicum spp. cultivars by Aphis gossypii is conferred by variation in volatile semiochemistry. Euphytica, 177, 299-307.

Darshanee, H.L.C., Ren, H., Ahmed, N., Zhang, Z.F., Liu, Y.H. \& Liu, T.X. (2017) Volatile-mediated attraction of greenhouse whitefly Trialeurodes vaporariorum to tomato and eggplant. Frontiers in Plant Science, $\mathbf{8}, 1285$.

Dawson, G.W., Griffiths, D.C., Pickett, J.A., Smith, M.C. \& Woodcock, C.M. (1984) Natural inhibition of the aphid alarm pheromone. Entomologia Experimentalis et Applicata, 36, 197-199.

Deletre, E., Chandre, F., Barkman, B., Menutc, C. \& Martin, T. (2015) Naturally occurring bioactive compounds from four repellent essential oils against Bemisia tabaci whiteflie. Pest Management Science, 72, 179-189.

Deletre, E., Schatz, B., Bourguet, D., Chandre, F., Williams, L., Ratnadass, A. \& Martin, T. (2016) Prospects for repellent in pest control: current developments and future challenges. Chemoecology, 26, $127-142$

Eigenbrode, S.D., Ding, H., Shiel, P. \& Berger, P.H. (2002) Volatiles from potato plants infected with potato leafroll virus attract and arrest the virus vector, Myzus persicae (Homoptera: Aphididae). Proceedings of the Royal Society B: Biological Sciences, 269, 455-460.

Foster, S.P., Tomiczek, M., Thompson, R., Denholm, I., Poppy, G., Kraaijeveld, A.R. \& Powell, W. (2007) Behavioural side-effects of insecticide resistance in aphids increase their vulnerability to parasitoid attack. Animal Behaviour, 74, 621-632.

Francis, F., Lognay, G. \& Haubruge, E. (2004) Olfactory responses to aphid and host plant volatile releases: $(E)-\beta$-Farnesene an effective kairomone for the predator Adalia bipunctata. Journal of Chemical Ecology, 30, 741-755.

Gaum, W.G., Giliomee, J.H. \& Pringle, K.L. (1994) Resistance of some rose cultivars to the western flower thrips, Frankliniella occidentalis (Thysanoptera: Thripidae). Bulletin of Entomological Research, 84, 487-492.

González-Coloma, A., Delgado, F., Rodilla, J.M., Silva, L., Sanz, J. \& Burillo, J. (2011) Chemical and biological profiles of Lavandula luisieri essential oils from western Iberia Peninsula populations. Biochemical Systematics and Ecology, 39, 1-8.

Halbert, S.E., Corsini, D., Wiebe, M. \& Vaughn, S.F. (2009) Plant-derived compounds and extracts with potential as aphid repellents. Annals of Applied Biology, 154, 303-307.

Hori, M. (1998) Repellency of rosemary oil against Myzus persicae in a laboratory and in a screenhouse. Journal of Chemical Ecology, 24, $1425-1432$

Hori, M. (1999a) The effects of rosemary and ginger oils on the alighting behavior of Myzus persicae (Sulzer) (Homoptera: Aphididae) and on the incidence of yellow spotted streak. Applied Entomology and Zoology, 34, 351-358.

Hori, M. (1999b) Antifeeding, settling inhibitory and toxic activities of labiate essential oils against the green peach aphid, Myzus persicae (Sulzer) (Homoptera: Aphididae). Applied Entomology and Zoology, 34, 113-118.

Hori, M. \& Komatsu, H. (1997) Repellency of rosemary oil and its components against the onion aphid, Neotoxoptera formosana 
(Takahashi) (Homoptera, Aphididae). Applied Entomology and Zoology, 32, 303-310.

Hwang, Y.-S., Wu, K.-H., Kumamoto, J., Axelrod, H. \& Mulla, M.S. (1985) Isolation and identification of mosquito repellents in Artemisia vulgaris. Journal of Chemical Ecology, 11, 1297-1306.

Isman, M.B. (2004) Plant essential oils as green pesticides for pest and disease management. Agricultural Applications in Green Chemistry, ACS Symposium Series (ed. by W. M. Nelson), Vol. 887, pp. 41-51. American Chemical Society, Washington, District of Columbia.

Isman, M.B., Wilson, J.A. \& Bradbury, R. (2008) Insecticidal activities of commercial rosemary oils (Rosmarinus officinalis) against Larvae of Pseudaletia unipuncta. and Trichoplusia ni. in relation to their chemical compositions. Pharmaceutical Biology, 46, 82-87.

Jiang, H., Wang, J., Song, L., Cao, X., Yao, X., Tang, F. \& Yue, Y. (2016) GCxGC-TOFMS analysis of essential oils composition from leaves, twigs and seeds of Cinnamomum camphora L. Presl and their insecticidal and repellent activities. Molecules, 21, 423.

Koschier, E.H. \& Sedy, K.A. (2003) Labiate essential oils affecting host selection and acceptance of Thrips tabaci lindeman. Crop Protection, 22, 929-934.

Lamy, F.C., Poinsot, D., Cortesero, A.-M. \& Dugravot, S. (2016) Artificially applied plant volatile organic compounds modify the behavior of a pest with no adverse effect on its natural enemies in the field. Journal of Pest Science, 90, 611-621.

Malézieux, E., Crozat, Y., Dupraz, C. et al. (2009) Mixing plant species in cropping systems: concepts, tools and models. A review. Agronomy for Sustainable Development, 29, 43-62.

Marin, M., Koko, V., Duletić-Laušević, S., Marin, P.D., Rančić, D. \& Dajic-Stevanovic, Z. (2006) Glandular trichomes on the leaves of Rosmarinus officinalis: morphology, stereology and histochemistry. South African Journal of Botany, 72, 378-382.

McCormick, A.C., Gershenzon, J. \& Unsicker, S.B. (2014) Little peaks with big effects: establishing the role of minor plant volatiles in plant-insect interactions. Plant, Cell \& Environment, 37, 1836-1844. Miresmailli, S., Bradbury, R. \& Isman, M.B. (2006) Comparative toxicity of Rosmarinus officinalis L. essential oil and blends of its major constituents against Tetranychus urticae Koch (Acari: Tetranychidae) on two different host plants. Pest Management Science, 62, 366-371.

Park, I.-K., Lee, S.-G., Choi, D.-H., Park, J.-D. \& Ahn, Y.-J. (2003) Insecticidal activities of constituents identified in the essential oil from leaves of Chamaecyparis obtusa against Callosobruchus chinensis (L.) and Sitophilus oryzae (L.). Journal of Stored Products Research, 39, 375-384.

Pausas, J.G., Alessio, G.A., Moreira, B. \& Segarra-Moragues, J.G. (2015) Secondary compounds enhance flammability in a Mediterranean plant. Oecologia, 180, 103-110.

Penvern, S., Bellon, S., Fauriel, J. \& Sauphanor, B. (2010) Peach orchard protection strategies and aphid communities: towards an integrated agroecosystem approach. Crop Protection, 29, 1148-1156.

Pichersky, E. \& Gershenzon, J. (2002) The formation and function of plant volatiles: perfumes for pollinator attraction and defense. Current Opinion in Plant Biology, 5, 237-243.

Rajabaskar, D., Ding, H., Wu, Y. \& Eigenbrode, S.D. (2013) Behavioral responses of green peach aphid, Myzus persicae (Sulzer), to the volatile organic compound emissions from four potato varieties. American Journal of Potato Research, 90, 171-178.

Rozman, V., Kalinovic, I. \& Korunic, Z. (2007) Toxicity of naturally occurring compounds of Lamiaceae and Lauraceae to three storedproduct insects. Journal of Stored Products Research, 43, 349-355.

Sadeh, D., Nitzan, N., Shachter, A., Chaimovitsh, D., Dudai, N. \& Ghanim, M. (2017) Whitefly attraction to rosemary (Rosmarinus officinialis L.) is associated with volatile composition and quantity. PLoS ONE, 12, e0177483.

Sanchez, J.A., La-Spina, M., Michelena, J.M., Lacasa, A. \& Hermoso de Mendoza, A. (2011) Ecology of the aphid pests of protected pepper crops and their parasitoids. Biocontrol Science and Technology, 21, $171-188$.

Satyal, P., Jones, T.H., Lopez, E.M. et al. (2017) Chemotypic characterization and biological activity of Rosmarinus officinalis. Food, $\mathbf{6}$, 20.

Sauge, M.-H., Grechi, I. \& Poëssel, J.-L. (2010) Nitrogen fertilization effects on Myzus persicae aphid dynamics on peach: vegetative growth allocation or chemical defence? Entomologia Experimentalis et Applicata, 136, 123-133.

Schröder, M.L., Glinwood, R., Webster, B., Ignell, R. \& Krüger, K. (2015) Olfactory responses of Rhopalosiphum padi to three maize, potato, and wheat cultivars and the selection of prospective crop border plants. Entomologia Experimentalis et Applicata, 157, 241-253.

Shrivastava, G., Rogers, M., Wszelaki, A., Panthee, D.R. \& Chen, F. (2010) Plant volatiles-based insect pest management in organic farming. Critical Reviews in Plant Sciences, 29, 123-133.

Staudt, M., Jackson, B., El-Aouni, H., Buatois, B., Lacroze, J.P., Poessel, J.L. \& Sauge, M.H. (2010) Volatile organic compound emissions induced by the aphid Myzus persicae differ among resistant and susceptible peach cultivars and a wild relative. Tree Physiology, 30, $1320-1334$

Storer, J.R. \& van Emden, H.F. (1995) Antibiosis and antixenosis of chrysanthemum cultivars to the aphid Aphis gossypii. Entomologia Experimentalis et Applicata, 77, 307-314.

Tang, G.B., Song, B.Z., Zhao, L.L., Sang, X.S., Wan, H.H., Zhang, J. \& Yao, Y.C. (2012) Repellent and attractive effects of herbs on insects in pear orchards intercropped with aromatic plants. Agroforestry Systems, 87, 273-285.

Tholl, D. \& Lee, S. (2011) Terpene specialized metabolism in Arabidopsis thaliana. Arabidopsis Book, 9, $\mathrm{e} 0143$.

Tomova, B.S., Waterhouse, J.S. \& Doberski, J. (2005) The effect of fractionated Tagetes oil volatiles on aphid reproduction. Entomologia Experimentalis et Applicata, 115, 153-159.

Uvah, I.I.I. \& Coaker, T.H. (1984) Effect of mixed cropping on some insect pests of carrots and onions. Entomologia Experimentalis Applicata, 36, 159-167.

Wang, W., Liu, Y., Chen, J., Ji, X., Zhou, H. \& Wang, G. (2009) Impact of intercropping aphid-resistant wheat cultivars with oilseed rape on wheat aphid (Sitobion avenae) and its natural enemies. Acta Ecologica Sinica, 29, 186-191.

Wang, G.P., Yu, X.D., Fan, J., Wang, C.S. \& Xia, L.Q. (2015) Expressing an $(E)$-beta-farnesene synthase in the chloroplast of tobacco affects the preference of green peach aphid and its parasitoid. Journal of Integrative Plant Biology, 57, 770-782.

Webster, B., Bruce, T., Pickett, J. \& Hardie, J. (2010) Volatiles functioning as host cues in a blend become nonhost cues when presented alone to the black bean aphid. Animal Behaviour, 79, 451-457.

Zhang, Z. \& Chen, Z. (2015) Non-host plant essential oil volatiles with potential for a 'push-pull' strategy to control the tea green leafhopper, Empoasca vitis. Entomologia Experimentalis et Applicata, 156, $77-87$

Zhang, Z., Bian, L., Sun, X., Luo, Z., Xin, Z., Luo, F. \& Chen, Z. (2014a) Electrophysiological and behavioural responses of the tea geometrid Ectropis obliqua (Lepidoptera: Geometridae) to volatiles from a non-host plant, rosemary, Rosmarinus officinalis (Lamiaceae). Pest Management Science, 71, 96-104.

Zhang, Z., Luo, Z., Gao, Y., Bian, L., Sun, X. \& Chen, Z. (2014b) Volatiles from non-host aromatic plants repel tea green leafhopper Empoasca vitis. Entomologia Experimentalis et Applicata, 153, $156-169$.

Zhang, R., Wang, B., Grossi, G. et al. (2017) Molecular basis of alarm pheromone detection in aphids. Current Biology, 27, 55-61.

Accepted 26 March 2019 